\title{
NEW AROMATIC POLYESTERPOLYOLS DERIVED FROM PET INDUSTRIAL WASTES
}

\author{
Eckhart Kornejew, Kiril Dimitrov, Michael Herzog
}

\section{Abstract}

China sent shock waves through the global recycling market last year when it announced it would no longer be accepting poor qualities of recyclable waste from foreign exporters - the so-called green fence action started in the beginning of year 2013. The answer should be a wave of innovation and investment in recycling technology to catalyze successful recycling markets in the west. This could include more sophisticated handling and treatment techniques and more high-technology processing plants. In the case of PET from returnable bottles we developed a process of chemical recycling to produce feedstocks for several technical applications. Aromatic polyester polyols (APP) are a major class of raw materials to produce polyurethanes.

\section{Zusammenfassung}

China hat den globalen Recycling-Markt letztes Jahr mit der Ankündigung geschockt, nicht länger niederwertige Qualitäten von rezyklierbaren Abfällen von ausländischen Exporteuren zu akzeptieren - die so genannte „Aktion Grüner Zaun“ startete zu Beginn des Jahres 2013. Die Antwort im Westen sollte ein Innovations- und Investitionsschub in Recycling-Technologie zur Entwicklung eines erfolgreichen Recycling-Marktes sein. Dies sollte hochentwickelte Behandlungstechnologien und installierte Anlagentechnik umfassen. Für PET-Getränkeflaschen aus den Pfandsystemen haben wir einen Prozess des rohstofflichen Recyclings entwickelt, mit dem Ausgangsstoffe für verschiedene technische Anwendungen gewonnen werden können. Die gewonnenen Aromatischen Polyesterpolyole (APP) dienen hierbei als Ausgangsstoffe zur Herstellung von Polyurethanen.

\section{INTRODUCTION}

There are four main classes of such polyester polyols (Randall, 2002): linear or lightly branched aliphatic polyester polyols with terminal hydroxyl groups, low molecular weight aromatic polyester polyols for rigid foam applications, polycaprolactones and polycarbonate polyols. The linear or lightly branched polyester polyols may be aliphatic or aromatic. Aromatic polyester polyols are produced from phthalic acid, isophthalic acid, or terephthalic acid. While the manufacture from phthalic or isophthalic acids is generally based on the monomers terephthalic acid oligomers may as well be produced from monomeric esters such as the dimethyl ester of terephthalic acid (DMT) or polyesters such as polyethylene terephthalate (PET), polybutylene terephthalate (PBT) or polypropylene terephthalate (PPT).

APP based on terephthalic acid are presently produced by two different ways: the transesterification of terephthalic acid dimethyl ester (DMT) or by the re-esterification of poly (ethylene terephthalate) (PET) with glycols of different origin (Vaidya 1991, Baglia 1989, Inada 1999). Due to the different raw materials APP of different quality will be obtained.

In this paper we report our experience with various types of post-consumer and industrial wastes of PET to produce APP, describe the quality obtained, and throw some light on the application of the materials obtained and their economic value.

\section{GENERAL PROCESS}

The reactor used is a stainless steel jacketed reactor with a volume of 0.1 to $10 \mathrm{~m}^{3}$ depending on the desired amount of APP to be produced. The reactor is equipped with a specially designed combination of demister, distillation column(s), and heat exchanger on top. The contents of the reactor are agitated by a stirrer at rather high speed. Further installations include a nitrogen inlet, a feed elevator, and a bottom valve with a filtering unit. The temperature is controlled via an oil heater with control unit.
The process is started with feeding the reactor with the necessary amount of diethylene glycol, catalyst and, if so necessary, with any additive used during the reaction. With stirring, the mixture is heated to about $180^{\circ} \mathrm{C}$ and any volatiles (mainly residual water) removed via the column condenser combination. When the volatile distillation ceases and the temperature is reached the PET is added via the elevating system. The PET is dissolved while rising the temperature to $250^{\circ} \mathrm{C}$. During the whole process the reactor is purged with nitrogen so that a constant stream of nitrogen is ensured. Any further volatiles are removed by the column condenser combination and collected on a balance. The transesterification reaction is performed at $250^{\circ} \mathrm{C}$ over a period of 3.5 to 6 hours depending on the type of material used. During the reaction time any volatiles are removed by the condenser and outlet and collected. After completion of the reaction the temperature is gradually lowered down to $180^{\circ} \mathrm{C}$ and the reaction product removed by the bottom valve via a filter unit into the storage containers. 
Some peculiarities of this process have to be considered. This is firstly to establish a functionality of the APP produced somewhat exceeding two by incorporating a calculated amount of a triol, in general glycerol, into the reaction mixture (Stoychev, 2006). By using only minor amounts of such a triol the viscosity of the final APP is not affected but the stability of the polyol is increased. Another feature of this process is to use only minor amounts of organo-metallic compounds as catalyst. In general, a mixture of tin and titanium compounds in the range of 15 to $30 \mathrm{ppm}$ is used but in special cases rare earth compounds may be added to accelerate the first stage of the reaction. For adjustment of the viscosity the mixture is balanced by the addition of some percent of aliphatic dicarboxylic acids such as adipic acid or sebacic acid (Behrendt, 1999). If these additives are used, there will be a short esterification step in the gap between the heating-up process and the addition of PET which usually lasts 30 to 60 minutes depending on the amount used. Furthermore, some renewable resources such as oils or modified oils maybe introduced into the process before PET is added to adjust properties of the APP, e. g. to improve the solubility of pentane or chlorinated hydrocarbons.

After receiving the calculated amount of distillates, mainly monoethylene glycol and some water, the cooling module of the reactor is started to cool the contents to about 200 to $180^{\circ} \mathrm{C}$ and filter them via a specially designed filter unit of two or three different filter modules. The number and type of filter modules depend on the PET material used.

\section{PET MATERIALS TO BE USED}

PET residues occur in several types and have to be analyzed according to the possible consequences for the overall reaction. At present, PET is mainly used to produce bottles or fibres with little amounts in engineering thermoplastics and bulk containers. We are here concentrating on the two main production variants.

PET for bottles is generally a high mo- lecular weight product with very little contamination meeting food regulations (e. g. acetaldehyde). Other products are not contained, the ethylene glycol used sometimes is combined with other diols. PET from such production is obtained in the form of blocks, fibres, dust, granules.

PET for fibres in general is doted with small amounts of silica and/or titanium dioxide both in micronized form. This leads to particles of less than $10 \mu \mathrm{m}$ which are difficult to filter off, either due to higher investment costs for the filter modules or by extended recovery time. The result of employing this material is usually a dispersion polyol containing the micronized solids.

PET from bottles, i. e. flakes from oneway or multi-way bottle recycling, occur in several colours and usually have some additives. These additives are not only dyestuffs or pigments to give blue, brown, green or yellow colours but more linings of the bottles with silanes (such as hexamethylene disiloxane), with intermediate layers from polyamides, or with outer layers of polyacetylenes. Since the silanes are forming a layer of few $\mathrm{nm}$ of silicates this is an inorganic substance which is as hardly to filter off as the additives for fibres. Any organic additive or layer will affect the reaction and the resultant APP. Main appearances for these are turbid or deeply coloured APP.

When using bottle grade PET from the production process of PET one has to make sure that the process is running the easiest way. To this end, blocks are milled to particles of 2 to $8 \mathrm{~mm}$ size by a mill delivered with the plant in case of using such material. In this case, the milled product is directly transferred to the silo and from there via the conveyer into the reactor. If granules are the basic material care has to be taken because of some percentages of dust in it. Thus the material has to be flushed with nitrogen to avoid dust explosions or electrostatic effects which are known to occur with polymeric dusts. After reacting the material according to the process described above there is need of only one filter module to get rid of some coarse impurities.
The bottle PET is delivered usually as preforms. Preforms usually do not contain any contamination and maybe used as such in the transesterification process. It has to be considered that the rather large pieces need a prolonged time in the dissolution stage so that a milling stage before the introduction into the reactor is recommended.

When using fibre PET from production lines as blocks or coils the inorganic solids have to be agglomerated during the process to be transformed into a filterable mode. To this end, certain filter aids are added in the end phase of the process at $250^{\circ} \mathrm{C}$ to absorb the micronized particles on their surface to give particle sizes between 200 and $800 \mu \mathrm{m}$ which are removed in a two module filter unit.

When using PET flakes from bottle recycling one has to take into consideration the various ways of bottle production for various liquids. As mentioned above, the layers lead to some problems when producing APP. If polyamides are used as an intermediate layer to decrease gas diffusion the APP may turn brown or dark due to reaction products of the polyamide. The polyamide is transesterified in a similar way as is PET leading to reactive oligomers. These are not affecting the properties of foams, but the colour of the APP only. More problems arise from layers in the $\mu \mathrm{m}$ or nanometer range. They lead to particles of less than $1 \mu \mathrm{m}$ of different properties so that only one filter aid will not be sufficient. In case of using such raw materials different filter aids have to be tested to find the optimum one for the raw material to be used in the respective plant and to make sure the filter unit works.

\section{PROPERTIES OF THE APP PRODUCED}

APP are produced for three main applications in polyurethane chemistry:

- polyisocyanurate foams (PIR) where a low hydroxyl number is desired and the functionality does not play an important role (hydroxyl numbers are in the range of 200 to 260 $\mathrm{mg} \mathrm{KOH} / \mathrm{g}$ ); 
- rigid polyurethane foams such as sandwich panels where a hydroxyl number somewhat higher as with PIR and a higher functionality are desired (hydroxyl numbers are in the range of 300 to $380 \mathrm{mg} \mathrm{KOH} / \mathrm{g}$ );

- polyurethane duromer foams where a hydroxyl number somewhat higher as with PIR and a higher functionality are desired (hydroxyl numbers are in the range of 300 to $360 \mathrm{mg} \mathrm{KOH} / \mathrm{g}$ );

Further applications are in the area of coatings, adhesives, sealants, and casts. For these products special polyester polyols have to be developed to exactly meet the requirements of the application.

By the process described several types of APP are produced (Schaffrath 2006). There are three main types according to the classification above which are characterized in Table 1.

Besides these lightly branched APP linear ones with a defined hydroxyl functionality of exactly 2 are available by proper adjustment of the reaction mixture. Examples of purely difunctional APP are given in Table 2.

Any of the APP has an inherent flame retardance due to the content of aromatic nuclei. A modification of the APP produced may be obtained for higher flame retarded polyurethanes by directly blending the APP with flame retardants such as liquid phosphorous compounds. When doing so, a second unit (blending station) should be considered to increase productivity of the overall process. In Table 3 some examples of APP blended with flame retardants are given.

Typically, the glycol used is diethylene glycol which results in APP with nearly only primary hydroxyl groups resulting in highly reactive polyols with an $\mathrm{OH}$-functionality of $\mathrm{fn}=2$. By introducing a triol such as glycerol or (trimethylol)propane into the polyethers the functionality may be increased to values of about $\mathrm{fn}=2.25$ but resulting in an increase in the viscosity of the products. Thus, the incorporation of triols has to be exer-

\section{Main types of APP}

\begin{tabular}{|c|c|c|c|}
\hline Parameter $\backslash$ APP & M20 & M21 & M22 \\
\hline Hydroxyl number $(\mathrm{mg} \mathrm{KOH} / \mathrm{g})$ & 240 & 320 & 380 \\
\hline Acid number $(\mathrm{mg} \mathrm{KOH} / \mathrm{g})$ & $<1$ & $<1$ & $<1$ \\
\hline Water content $(\%)$ & $<0,2$ & $<0,2$ & $<0,2$ \\
\hline Viscosity $\left(25^{\circ} \mathrm{C}\right)(\mathrm{mPas})$ & 8,000 & 4,500 & 4,500 \\
\hline Functionality & 2.03 & 2.05 & 2.07 \\
\hline
\end{tabular}

Tab. 1) Main types of APP.

Linear APP

\begin{tabular}{|c|c|c|c|}
\hline Parameter $\backslash$ APP & A31 & A42 & A46 \\
\hline Hydroxyl number $(\mathrm{mg} \mathrm{KOH} / \mathrm{g})$ & 220 & 320 & 380 \\
\hline Acid number $(\mathrm{mg} \mathrm{KOH} / \mathrm{g})$ & $<1$ & $<1$ & $<1$ \\
\hline Water content $(\%)$ & $<0,2$ & $<0,2$ & $<0,2$ \\
\hline Viscosity $\left(25^{\circ} \mathrm{C}\right)(\mathrm{mPas})$ & 5,500 & 4,000 & 3,500 \\
\hline Functionality & 2.00 & 2.00 & 2.00 \\
\hline
\end{tabular}

Tab. 2) Linear APP.

Flame Retarded APP

\begin{tabular}{|c|c|c|c|}
\hline Parameter $\backslash$ APP & F03 & F04 & F06 \\
\hline Hydroxyl number $(\mathrm{mg} \mathrm{KOH} / \mathrm{g})$ & 260 & 330 & 390 \\
\hline Acid number $(\mathrm{mg} \mathrm{KOH} / \mathrm{g})$ & $<1$ & $<1$ & $<1$ \\
\hline Water content $(\%)$ & $<0,2$ & $<0,2$ & $<0,2$ \\
\hline Viscosity $\left(25^{\circ} \mathrm{C}\right)(\mathrm{mPas})$ & 3,500 & 2,000 & 1,500 \\
\hline Functionality & 2.03 & 2.04 & 2.05 \\
\hline
\end{tabular}

Tab. 3) Flame Retarded APP.

APP with high content of secondary hydroxyl groups

\begin{tabular}{|c|c|c|c|}
\hline Parameter $\backslash$ APP & H62 & H65 & H66 \\
\hline Hydroxyl number $(\mathrm{mg} \mathrm{KOH} / \mathrm{g})$ & 220 & 320 & 360 \\
\hline Acid number $(\mathrm{mg} \mathrm{KOH} / \mathrm{g})$ & 0.35 & 0.30 & 0.30 \\
\hline Water content (\%) & $<0,1$ & $<0,1$ & $<0,1$ \\
\hline Viscosity $\left(25^{\circ} \mathrm{C}\right)(\mathrm{mPas})$ & 7,900 & 4,400 & 2,900 \\
\hline Functionality & 2.00 & 2.00 & 2.00 \\
\hline
\end{tabular}

Tab. 4) APP with high content of secondary hydroxyl groups. 
cised carefully so as not to increase the viscosity beyond a tolerable limit.

Otherwise, APP with a majority of secondary hydroxyl groups is obtained by properly choosing the glycol component. One approach successfully applied is the use of 2-ethylhexane-1,3-diol together with terephthalic acid or esters (Fulev, 2007). By this type of process APP of rather low hydroxyl and acid numbers are produced using a similar process and equipment as described. Table 4 depicts some results.

The polyols of Table $\mathbf{4}$ were produced by a transesterification process employing terephthalic acid dimethyl ester (DMT) as starting material. They were designed to meet the requirements of sealants with pot lives extending 20 minutes.

\section{APPLICATION OF THE APP}

The application of the APP produced in variants of this general transesterification process is in nearly any field of rigid polyurethanes. So, the properties of the polyols can be carefully adjusted to the application of the client. In Table 5 some general rules for application are exemplified.

By employing different combinations and ratios of the raw materials named one is able to meet exactly the conditions the respective client needs. Furthermore, based on such a broad range of properties of the APP it is possible to formulate nearly any rigid polyurethane system of high performance. Thus, when employing the M20 combined with a proper formulation at an isocyanate index of about 500 extraordinary thermally stable PIR foams can be produced. It was proved with such a formulation to receive a foam in the density region of $40 \mathrm{~g} / \mathrm{cm}^{3}$ being stable in the range of -190 to $+190^{\circ} \mathrm{C}$ showing a deviation in the three spatial directions of less than $1.5 \%$.

\section{ECONOMY OF APPLICATION OF APP}

When considering the production and

\begin{tabular}{|c|c|c|c|}
\hline APP & $\begin{array}{l}\text { Hydroxyl-No. } \\
\text { range (mg KOH/g) }\end{array}$ & $\begin{array}{l}\text { Field of application } \\
\text { recommended }\end{array}$ & Peculiarities \\
\hline M20, A31 & $220-240$ & PIR-Foams & $\begin{array}{c}\text { Isocyanate indexes } \\
\text { between } 300 \text { and } \\
600\end{array}$ \\
\hline F03 & $250-270$ & $\begin{array}{l}\text { PIR-Foams, flame } \\
\text { retarded duromers }\end{array}$ & $\begin{array}{l}\text { For use in flame } \\
\text { retarded foams }\end{array}$ \\
\hline $\mathrm{H} 62$ & $200-240$ & $\begin{array}{c}\text { Sealants, Adhe- } \\
\text { sives }\end{array}$ & $\begin{array}{l}\text { Low reactivity } \\
\text { polyol }\end{array}$ \\
\hline $\mathrm{M} 21, \mathrm{~A} 42$ & $300-340$ & $\begin{array}{l}\text { Duromers, panel } \\
\text { foams }\end{array}$ & - \\
\hline F04 & $300-340$ & $\begin{array}{l}\text { Duromers, panel } \\
\text { foams }\end{array}$ & $\begin{array}{l}\text { To adjust the } \\
\text { degree of flame } \\
\text { retardance }\end{array}$ \\
\hline $\mathrm{M} 22, \mathrm{~A} 46$ & $360-400$ & $\begin{array}{l}\text { Rigid foams, panel } \\
\text { foams }\end{array}$ & - \\
\hline F06 & $380-400$ & $\begin{array}{l}\text { Flame retarded } \\
\text { rigid foams, panel } \\
\text { foams }\end{array}$ & $\begin{array}{l}\text { To adjust the } \\
\text { degree of flame } \\
\text { retardance }\end{array}$ \\
\hline $\mathrm{H} 65, \mathrm{H} 66$ & $320-380$ & Sealants, coatings & $\begin{array}{l}\text { Low reactivity } \\
\text { polyol }\end{array}$ \\
\hline
\end{tabular}

Tab. 5) Application of aromatic polyester polyols.

use of such APP not only ecologic and technical aspects have to be considered. Emphasis is on the economy of the process and its products.

The costs of the process are to a great extent determined by raw material costs. The prices of the additives used in the various processes, ethylene glycol, adipic acid, glycerol, catalysts a.s.o. increased during the last years by 25 to $50 \%$. E.g. ethylene glycol rose to about $1100 € / \mathrm{t}$, adipic acid to nearly $1700 € /$ t.

The PET wastes considered here are in the range between 0 and $850 € / \mathrm{t}$ depending on the type. The Chinese Green Fence Action further enhances the pressure to the prices of European plastics recycling materials. Any PET manufacturer produces some 1.5 to $3 \%$ of the total production as waste, of which only minor amounts are a valuable good to be purchased by customers. Most of these wastes have to be treated as "true" waste and either be incinerated or brought to a landfill as long as this works.

A rough calculation of the production costs leads, of course, to a dependence on the amount of APP produced. Considering a 4,000 t/a plant, the production costs are in the range of $850 € / \mathrm{t}$ (with the PET calculated with $300 € / \mathrm{t}$ ). At higher production levels these costs may be as low as $700 € / t$ and when receiving PET at no costs even at $630 € / \mathrm{t}$. The market price of high quality APP (i. e. nearly colourless, clear) is between 1550 and $1850 € /$ t. So, for any PET producer the performance of such a process will be of benefit both with respect to the waste deployment and to profit from a side stream.

\section{CONCLUSION}

In this paper we reported on work of the development of a new group of APP based on the transesterification of poly(ethylene terephthalate) with glycols and triols by a new process and, 
based thereon a concept for a new plant, which resulted in new types for application in nearly any field of rigid polyurethanes production. The basic PET best used is material from industrial production to make nearly no problems in transesterification and having the highest profit marges. In case of fibre or bottle PET additional problems arise from contaminants which have to be overcome by newly developed treatment steps at the end of the process combined with a new technology to perform these process steps. The APP produced this way lead to high performance polyurethanes with outstanding properties. Furthermore, the APP are produced with very good economy especially when using in-house wastes of the PET production and produce the APP as a side stream.

\section{LITERATURE}

Baglia, S., Wong, W. T. Depolymerization of polyethylene terephthalate recycled from post-consumer softdrink bottles, J. Polym. Sci, Part A 27, S. 2071-2082 (1989)

Behrendt, G., Pohl, M., Polyesterpolyole mit niedriger Viskosität, DE-Anm. 19915128.8 vom 25. 03. 1999

Fulev, S., Boyadzhiev, M., (Recyclit GmbH), Verbessertes Verfahren zur Herstellung aromatischer Polyesterpolyole mit überwiegend sekundären Hydroxylgruppen aus PET und diese Polyole, DE-Anm. 102007063442.2 (21. 12. 2007)

Inada, Sh., Sato, K. (Ales Co., Ltd.), Methods for the Preparation or Purification of Bis-(ß-hydroxyethyl) terephthalate, EP 1120394 (24. 12. 1999)

Randall, D., Lee, S. The Polyurethanes Book, p. 107, J. Wiley \& Sons (2002)

Schaffrath, R., Langenstrassen, R., Schmidt, K.-H., Fulev, S., Skokova, L., Behrendt, G., A New Group of Aromatic Polyester Polyols Derived from PET Industrial Wastes and Their Application in the Polyurethane Industry, Polyurethanoviye tekhnologyi 10, 22-24, (2006)

Stoychev V. (Recyclit GmbH), Neue Polyurethanharze und Verfahren zu ihrer Herstellung, DE-Anm. 102006 038259.5 vom 08. 08. 2006

Vaidya, U., R., Nadkarni, V. M. Polyester polyols from PET waste: effect of glycol type on kinetics of polyesterification in J. Appl. Polym. Sci. 38, 1179-1190 (1991)

\section{AUTHORS}

Dipl.-Chem. Eckhart Kornejew

Fachbereich Ingenieur- und Naturwissenschaften Technische Hochschule Wildau [FH]

eckhart.kornejew@th-wildau.de

\section{MSc Kiril Dimitrov}

Fachbereich Ingenieur- und Naturwissenschaften Technische Hochschule Wildau [FH]

kiril.dimitrov@th-wildau.de

Prof. Dr. rer. nat. Michael Herzog

Fachbereich Ingenieur- und Naturwissenschaften

Technische Hochschule Wildau [FH]

michael.herzog@th-wildau.de 